\title{
Controlling the Size and Composition of Iron Nanoparticles for Carbon Nanotube Growth
}

See Wee Chee* and Renu Sharma ${ }^{+}$

* LeRoy Eyring Center for Solid State Science, Arizona State University, Tempe, AZ 85287

${ }^{+}$National Institute of Standards and Technology, Gaithersburg, MD 20899

Carbon nanotubes (CNT) are promising material for making electron field emission sources [1] but one of the key challenges has been the synthesis of arrays of nanotubes with controlled size and placement. Recently, we reported the site-specific deposition of Fe catalyst particles using electron beam induced deposition (EBID) in an environmental scanning/transmission electron microscope $(\mathrm{E}(\mathrm{S}) \mathrm{TEM})$ [2]. The column of the $\mathrm{E}(\mathrm{S}) \mathrm{TEM}$ can also be used as a reactor for CNT formation in which the nucleation and growth processes can be directly observed with atomic resolution [3]. For chemical vapor deposition, the catalyst size is one of the factors that determine the size of the CNT. In this study, we examine how the size of the nanoparticles fabricated for CNT growth using EBID can be controlled using different deposition conditions.

A Tecnai F20 E(S)TEM was used for both EBID and CNT growth. The substrates were perforated $\mathrm{SiO}_{2}$ membranes. Two organometallic precursors were used as Fe sources; diiron nonacarbonyl $\left(\mathrm{Fe}_{2}(\mathrm{CO})_{9}\right)$ and ferrocene $\left(\mathrm{Fe}\left(\mathrm{C}_{5} \mathrm{H}_{5}\right)_{2}\right)$. For this study, we varied three deposition parameters; temperature, pressure and deposition time. Inlet gas pressures from $0.06 \mathrm{~Pa}$ to $0.33 \mathrm{~Pa}$ and substrate temperatures up to $450^{\circ} \mathrm{C}$ were used. Composition of the deposited particles was obtained from electron energy loss spectroscopy (EELS) data. As reported earlier [2], the catalyst nanoparticles are heated in $13 \mathrm{~Pa}$ of hydrogen up to $650^{\circ} \mathrm{C}$ prior to introducing acetylene for CNT growth.

In Figure 1, we show an example of Fe nanoparticles deposited in a patterned array using EBID and the line profiles used to measure the diameter of these particles. As expected, we observe that the diameter increases with deposition times. However, at diameters greater than $\sim 18 \mathrm{~nm}$, the growth morphology goes from lateral growth to vertical growth, leading to dendrite-like structures. For diiron nonacarbonyl, the deposit diameter showed weak dependence on both temperature and pressure. In addition, at substrate temperatures above $100^{\circ} \mathrm{C}$, the precursor decomposed thermally, resulting in the deposition of a Fe film. Using ferrocene, we were able to deposit particles up to $450^{\circ} \mathrm{C}$. As shown in Figure 2(a) the deposited particle diameter decreased with increasing substrate temperature. At room temperature and $150^{\circ} \mathrm{C}$, the particle diameter showed only weak pressure dependence and long deposition times resulted in dendritic growth. On the other hand, at $300^{\circ} \mathrm{C}$ and $450^{\circ} \mathrm{C}$, the deposited particle diameter showed a marked increase with pressure (in Figure 2(b)). Lastly, we observe from the EELS data (given in Figure 3) that the particles deposited using ferrocene has a much higher carbon content compared to particles deposited using diiron nonacarbonyl and the carbon content is not significantly reduced by higher deposition temperatures. The effect that composition of these particles has on their activity for carbon nanotube growth will also be presented.

References:

[1] N. de Jonge, J.M. Bonard, Phil. Trans. R. Soc. Lond. A 362 (2004) 2239

[2] R. Sharma et al, Nano Lett. 9 (2009) 689 
[3] R. Sharma, J. Mater. Res. 20 (2005) 1695

[4] Funding from NSF-CBET \#0625340. The use of facilities in the LeRoy Eyring Center for Solid State Science at Arizona State University is gratefully acknowledged.

[5] The full description of the procedures used in this abstract requires the identification of certain commercial products and their suppliers. The inclusion of such information should in no way be construed as indicating that such products or suppliers are endorsed by NIST or are recommended by NIST or that they are necessarily the best materials, instruments, software or suppliers for the purposes described.

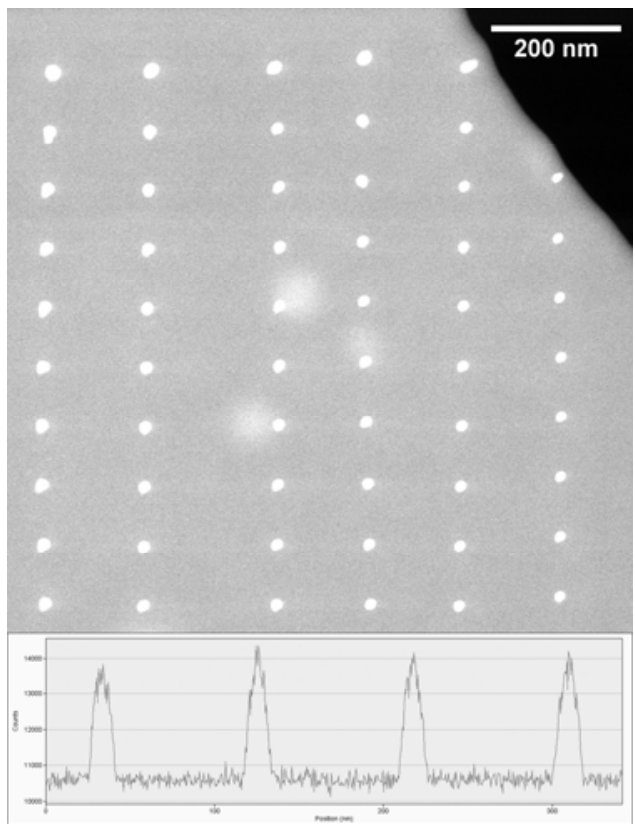

Figure 1. Annular dark field image (top) of an array of Fe particles of $\sim 16 \mathrm{~nm}$ diameter deposited using ferrocene as measured from a line profile (bottom)

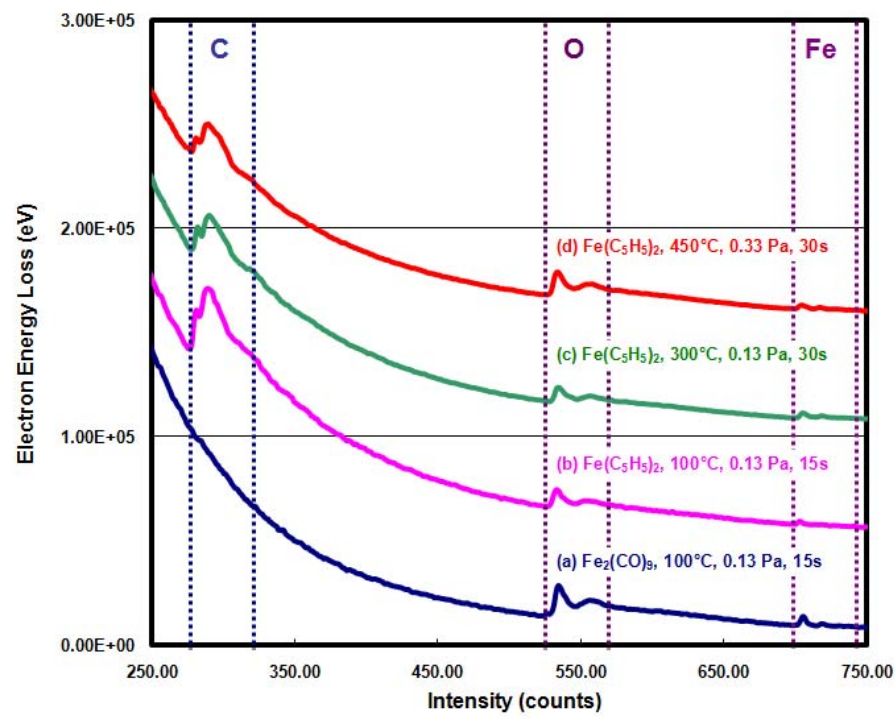

Figure 3. EELS Spectra from nanoparticles deposited using (a) diiron nonacarbonyl at $100^{\circ} \mathrm{C}, 0.13 \mathrm{~Pa}, 15 \mathrm{~s}$ and using ferrocene at (b) $100^{\circ} \mathrm{C}, 0.13 \mathrm{~Pa}, 15 \mathrm{~s}$, (c) $300^{\circ} \mathrm{C}, 0.13 \mathrm{~Pa}, 30 \mathrm{~s},(\mathrm{~d}) 450^{\circ} \mathrm{C}, 0.33 \mathrm{~Pa}, 30 \mathrm{~s}$
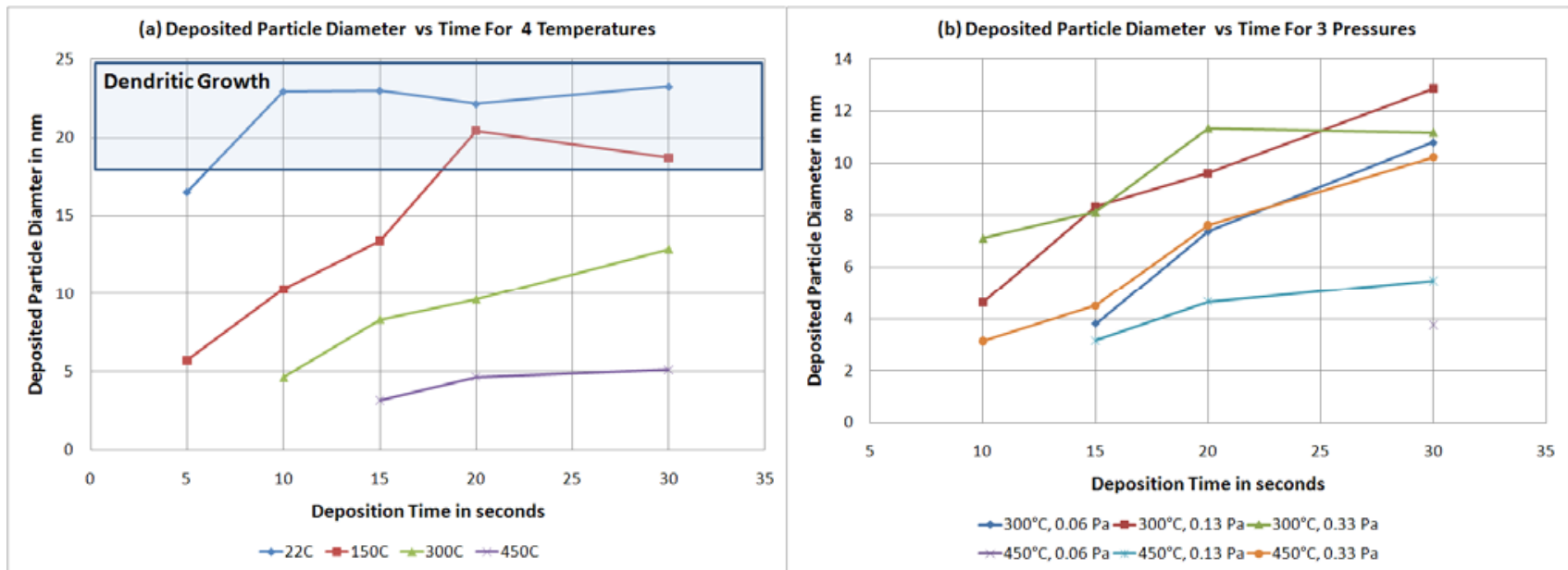

Figure 2. Diameter of particle deposited using ferrocene as a function of deposition time for (a) 4 different temperatures using $0.13 \mathrm{~Pa}$ inlet pressure and (b) 3 different pressures at $300^{\circ} \mathrm{C}$ and $450^{\circ} \mathrm{C}$ (for dendritic growth, the diameter is measured from the base of the deposit) 